service should be separated from the ear, nose, and throat departments. Where several hospitals are close together, one should be selected to receive all eye cases, and in a similar way the several ophthalmic surgeons can be grouped. Such a plan was carried out in Base Hospital 36 for the Vittel and Contrexèville areas, and in Base Hospital 46 for the Bazoilles group. A permanent record of refraction done at home should accompany the soldier going abroad, and in the case of officers is best carried with his personal papers and pasted inside the cover of the soldier's pay book. The instrumental equipment is specified, and we note that the Lancaster type of magnet is alone included in the list.

\title{
ABSTRACTS
}

\section{I.-MYOTONIC DYSTROPHY}

Fleischer, Bruno (Tübingen).-Myotonic dystrophy (myotonia atrophica) with cataract. (Ueber myotonische Dystrophie mit Katarakt.) Arch. f. Ophthal., Vol. XCVI., parts i and ii., I918.

Fleischer here gives a careful account of myotonic dystrophy, of which thirty-eight cases have been observed in the Tübingen Clinic since 1901, with special reference to the occurrence of cataract. He gives in tabular form an analysis of his cases according to the various symptoms, as well as a number of tables to illustrate the hereditary nature of this affection.

The author sums up his remarks as follows:

Pre-senile cataract appearing at the age of 25 to 45 years is frequently a symptom of this disease.

The disease is distinguished by muscular and general symptoms, atrophy of certain muscles of the head and neck, forearms, and small muscles of the hand, extending later to the lower extremities, trunk, and finally affecting the musculature of almost the entire body, and myotony in the muscles of the hand, tongue, and jaw; atrophy or degeneration of the thyroid glands, general emaciation, atrophy of the pharyngeal muscles with consequent disturbance of speech and deglutition, cataract, vasomotor disturbances, baldness in males, atrophy of testicles, sexual disturbances in both sexes, and mental and moral deterioration.

This affection is steadily progressive, it rarely begins before the age of 25 and usually before the fiftieth year, leads to death, which not infrequently supervenes at a much earlier date from intercurrent disease. In the cases associated with cataract, it appears in females most frequently between the ages of 25 and 35, and in males 
between 35 and 45 . The incipient signs of cataract are observed in the earliest stages of the disease.

The examination of families has shown that myotonic dystrophy is a markedly familial hereditary aftection, the germ of which can be traced back for five or six generations. The heredity is homochronous and homologous. This disease, therefore, belongs to the group of typical familial-hereditary diseases of a degenerative character.

Other signs of the disease. in descending series of generations are to be found particularly in the appearance of pre-senile cataract, in the generation preceding the myotonia, without other symptoms of myotonic dystrophy - usually at a more advanced age than in the phase of myotonic degeneration-or sometimes of a simple senile cataract in still earlier generations. To these may be added an increased infant mortality, childless marriages, celibacy, so that certain branches of the families die out and hence the disease disappears.

The cataract cannot be regarded as the sign of a latent tetany owing to the difference in its form from that of tetany; but, like the latter, it very probably owes its origin to an aftection of the glands of internal secretions.

(In myotonic dystrophy the cataract begins in the posterior cortex with opacity of the posterior pole and radiating striae in the form of a star; similar changes then appear in the anterior cortical layers, accompanied by very fine punctate opacities throughout the lens substance. This condition then develops fairly rapidly into a complete soft cataract with a small nucleus, corresponding to the age of the patients. In tetany the lens frequently shows a large hard nucleus and the cataract commences with opacities in a supranuclear zone similar to those found in lamellar cataract.)

With the probability of this origin the appearance of cataract, pre-senile and senile, in earlier generations acquires special significance for the pathogenesis of the disease which, owing to the presence of disturbances of internal secretion in conjunction with dystrophic and myotonic symptoms, is of great theoretical interest, especially when the probability of changes in the central nervous system is taken into consideration. The question of the connection between the disturbances in the glands of internal secretion and - the aflection of the muscles and probable disease in the central nervous system must be reserved for further research when the pathological anatomy of this disease has been made clear.

By reason of its relation to changes in the glands of internal secretion the cataract of myotonic dystrophy is of very great interest for the problem of the aetiology of cataract in general.

The author appends a long list of references to the literature of the subject, and shows in several plates photographs illustrative of the myotonic facies and other features of the disease.

Thomas SNowball. 


\section{II.-MACUL.AR VISION IN HEMIANOPIA}

(I) Van Schevensteen, A.- Traumatic incomplete left homonymous hemianopsia or quadrant anopsia with conservation of the macular visual fields and pure word blindness. (Hémianopsie homonyme gauche traumatique incomplète ou anopsie en quadrant avec conservation des champs visuels maculaires et cécité verbale pure.) Ann. d'Oculist., June, 1916.

(1) A. Van Schevensteen, junior, records the case of a lefthanded soldier in whom a fracture of the right parieto-occipital region of the skull by a shrapnel bullet was followed by homonymous hemianopic defects in the left lower quadrants of his fields of vision. The macular fields were not involved, and the colour fields within the areas in which vision was retained were normal. The injury caused unconsciousness, and on coming to himself, the patient was blind. He gradually recovered his sight, but his visual acuity never got better than 0.3 in each eye. The defects in the visual fields remained unaltered for three months. The patient could recognise printed or written letters easily, and could read usual words of one or two syllables, but could not understand polysyllabic words or put a sentence together. The internal visual image of words was retained. In writing he had great difficulty in keeping on the lines. He copied printed letters one by one, and at the end of a couple of hours he could only read some one- or two-syllable words in his copy. As is well known, the cortical centre for the mental representation of ideas in right-handed subjects is situated in the left hemisphere, and word-blindness therefore normally accompanies injuries of the left side of the head, and is associated with right hemianopsias ; but in the present case the patient being left-handed word blindness was caused by a lesion of the right side of the head, and was associated with left hemianopsia. The case contrasts with one previously reported by the author* in which an injury to the right parieto-occipital region of a right-handed man caused hemianopic defects in the left lower quadrants without great difficulty in reading:

$$
\text { R. J. Coulter. }
$$

(2) Vinsonneau, Angers.-Central vision in hemianopics with intact macular zone. (La vision maculaire chez les hémianopsiques à zone maculaire intacte.) Arch. d'Ophtal., September-October, 1916.

(2) Cases of hemianopia due to wounds of the skull by firearms have attracted the close attention of ophthalmologists during the

*Arch. d'Ophtal., 1907, p. 158. 
present war. In a paper published in November, 1915 (Arch. d'Ophtal., Nov.-Dec., 1915, p. 785), Terrien and Vinsonneau devoted special attention to the condition of central vision in cases of hemianopia due to wounds of the skull received in battle. An unexpected result of their investigations, to which they directed attention, was that in a number of observations in cases of homonymous hemianopia with preservation of macular vision, the visual acuity of the eye on the same side as the loss of field (right eye in right hemianopia, left eye in left hemianopia) was lowered to a greater degree than that of the eye on the opposite side; in other words, the eye on the same side as the cranial lesion suffered less deterioration of central vision than did the eye on the opposite side. A study of cases published by others seems to confirm these observations and the authors propose to deal more fully with all recorded cases bearing on this symptom after the war. They have already suggested a possible anatomical explanation of the unequal deterioration of vision which they propose to discuss anew in their later work.

J. B. LAWFORD.

(3) Cerise, L.- Two cases of double hemianopia with preservation of macular vision. (Deux cas d'hémianopsie double avec conservation de la vision maculaire.) Arch.d'Ophtal., September-October, 1916.

In the meantime Cerise reports two additional cases which exhibit an inequality of central vision in favour of the eye on the side of the cerebral lesion. (1) Wound by a shell splinter in the left upper occipital region. Right homonymous hemianopia : right eye $\mathrm{V}:=4 / 10$, left eye $\mathrm{V} .=7 / 10$. (2) Wound by a fragment of shell in the left upper occipital region. Right homonymous hemianopia; with preservation of the macular zone: right eye $V .=4 / 10$, left eye $\mathrm{V} .=6 / 10$. J. B. LAWFORD.

\section{III.-EYE CHANGES IN TRENCH NEPHRITIS}

\section{Kirk, J. (late R.A.M.C.) - Eye changes in trench nephritis} Brit. Med. Jl., January 5, 1918.

Kirk examined the eyes of 70 or 80 cases of trench nephritis chiefly in soldiers between 20 and 30 years of age, who for the most part were seriously ill of the disease. As a result of examination of the eyes the cases were classified by the author in three groups, A, B, and C. Group A numbered about 21 men, all convalescent, and in 4 only of them $(19 \%)$ were slight retinal changes foundsmall spots of exudation, a punctate haemorrhage, slight haziness 
of the optic disc, or a little oedema along the course of the veins. Group B included about 20 patients, with some albumin in the urine, breathlessness, and oedema, and of these cases $8(40 \%)$ showed minor retinal changes, but 1 suftered from a somewhat severe neuro-retinitis. Group C, 13 in number, had nephritis in marked form, and of these 4 had severe and 4 slighter retinal changes $(61 \%)$. As regards the retinal changes Kirk notes that the spots of exudation were near the disc and in the macular region, although the star-like figure familiar to ophthalmic surgeons was not observed; haemorrhages were uncommon; the optic disc was often affected; small areas of oedema were present along the veins; and, lastly, the gradual absorption of the smaller patches of exudation could be followed in several instances. Kirk sums up by saying that in trench nephritis the retina is very liable to be involved; that the changes are probably due to a specific toxin; that the retinal deposit tends to clear up in most cases; and that the retinal condition is allied to the acute retinitis of pregnancy, scarlatina, and acute toxaemia, and should not be confounded with the retinitis of chronic nephritis with its permanent changes in the retinal vessels and tissues.

S. S.

\section{IV.-FLAVINE}

\section{Lawson, Arnold (London).-Flavine in Ophthalmic Surgery Lancet, June 28, 1919. (Ophthal. Soc., May, 1919).}

Ophthalmic surgeons everywhere will be much interested in Lawson's article upon the use of flavine in eye work. It is a clinical and at the same time a critical article in which the author simply states his experiences of the class of case in which this drug is of service, and of the class of case in which it is not.

Flavine is employed in one or two forms, namely acriflavine (methyl chloride of diamino-acridine) and proflavine (hydrochloride or sulphate of diamino-acridine). Both are potent antiseptics, the bactericidal action of which is enhanced by admixture with serum. They are comparatively nontoxic both locally and generally. In concentrated solutions proflavine is the less irritating and this, in a standard solution of 1 in 1000 normal saline, is what the author has employed. If, however, the solution is to be used for more than two or three days this strength becomes slightly irritating and should be reduced to 1 in 4000 . The author divides his experiences into "Wounds" and "Inflammatory Conditions" of the eye. In this connection it is pointed out and insisted upon that flavine is to be regarded rather as an antiseptic than as a disinfectant. It is to 
be used to prevent sepsis rather than to cure it. Consequently its use in wounds is much more valuable than in inflammatory conditions. There are four classes of wounds in which Lawson has found flavine " of the highest value," namely, wounds caused by foreign bodies, operations requiring sutures, operations on "dirty" eyes, and as a dressing for grafts.

With regard to the first heading, the author makes the remarkable statement that in the two years during which he has employed flavine he has not met with a single case, coming under early treatment, which has given rise to trouble on the ground of sepsis. Again, in squint operations, for example, "troubles with sutures will vanish if flavine is dropped into the eye immediately after the operation, and its use steadily continued during the wound healing." With regard to operations on dirty eyes the author's words may again be quoted. "Perhaps this point most frequently arises in some cases of perforation of the cornea with extrusion of the iris and in a certain number of cases of acute congestive glaucoma. In both of these classes the danger of sepsis spreading to the wound edges, and so to the interior of the eye, is, I believe, very sensibly diminished by the use of flavine at the time of operation, and. for a couple of days or so after the operation. In such cases a solution of 1 in 1000 can be safely used and is to be preferred to a weaker one."

With regard to grafts Lawson is also quite specific in his statement :- " The surface to be grafted, after bleeding has been stopped, should be well swabbed over with flavine (1 in 1000), and strips of gauze well soaked in flavine should be laid over the graft when applied. This dressing need not be touched for several days. All that is necessary is to moisten the gauze dressing with fresh flavine from time to time. In the case of Thiersch grafts, where it is most desirable not to interfere with the graft for at least a week, I prefer to use for the dressing itself the weaker solution of flavine ( 1 in 4000) rather than the stronger ( 1 in 1000), and have found it perfectly efficacious."

With regard to inflammatory conditions of the eye, such as conjunctivitis, flavine alone is not to be relied upon. It is not a good disinfectant. - It may be used in combination with the usual remedies. Lawson makes the interesting suggestion that flavine might be found to be a better and safer prophylactic than silver nitrate against ophthalmia neonatorum. He has not had an opportunity of testing it in this respect, and if one might offer a friendly criticism, it is that the sentence "I would commend its trial to midwives and doctors" is in need of emendation. The author considers, from his personal experience, that the use of flavine ( 1 in 4000 ) is of value in actual ophthalmia neonatorum, in that it protects the cornea from invasion. He employs a drop of the weak solution after each irrigation of the eye. In corneal 
ulcerations there is, as a rule, no advantage in the use of flavine, but in hypopyon ulcer a solution of flavine can be quite safely used to wash out the anterior chamber. In relapsing blepharitis an ointment of proflavine oleate ( 1 in 1000) had a very good effect in one case, but the author does not feel justified in making positive statements as to its use in such conditions.

ERNEST THOMSON.

\section{V.-PREVENTIVE LEGISLATION}

\section{(1) Allport, Frank (Chicago). - State legislation concerning wood alcohol. Ophthalmology, July, I9I6.}

(1) This is the fourth of a series of papers by Allport, dealing with legislation in the United States in its relation to ophthalmology.

It is now well known that wood alcohol, or methyl alcohol, when either imbibed or inhaled can produce serious toxic symptoms, leading to blindness and even to death. Wood alcohol is obtainable on the market in three forms: (1) in its raw, unpurified form, which is so foul smelling and disgusting to taste that there is little danger that it will be used for drinking purposes; (2) denatured, industrial, or domestic alcohol (our " methylated spirit"), mainly composed of ethyl alcohol, but with enough methyl alcohol added to render it unfit for consumption; and (3) various forms of deodorised or purified wood alcohol, known as Columbian spirits, Colonial spirits, etc., from which the odour, taste, and colour of wood alcohol have been removed, but without reduction of its intensely poisonous character.

In the United States especially there have been a large number of cases of wood alcohol poisoning due to the internal use of one or other of these forms of deodorised wood spirits. The danger of such an occurrence is much increased by the fact that these are often sold without warning as to the poisonous nature of the material and under descriptions which disarm suspicion, for example: "A pure, refined spirit for domestic use," "A perfect substitute for grain alcohol." The main point in Allport's paper is that it is unnecessary to run the risks attached to the use of this substance, since denatured alcohol is equally cheap, is easy to obtain, and does not involve the same dangers.

Within the last ten years eftorts have been made by legislation throughout the United States to limit the use of wood alcohol. This paper contains a summary of the laws of the different States dealing with the subject. Although these laws are, for the most part, quite clear, and their intention is well known, it would not be difficult, as Allport points out, to evade them. He goes so far as to 
suggest that the manufacture of "purified" wood alcohol should be stopped, or, if it is indispensable for certain industries, it should pass straight from the manufacturer to the industry concerned, and should be kept out of the hands of retail dealers.

A. J. Ballantyne.

(2) Allport, Frank (Chicago).-State legislation concerning shop lighting, shop accidents, shop conditions, the common towel, etc. Ophthalmology, October, 1916 .

(2) In this article (the fifth of the series), Allport points out that all measures which prevent disease or injury of the eyes in industrial life are not only beneficial to the workers, but also promote economy by increasing efficiency and output.

Some of the measures to which he draws attention are : suitable and efficient lighting, provision of goggles for protection against foreign bodies or against excessive heat and light, the fitting of protecting hoods and air suction in connection with grinding wheels, and the employment of secure joints in leather belting. He advocates the abolition of the unskilled "shop oculist," and also speaks in favour of the systematic examination of the eyes of industrial recruits, and the fitting, where necessary, of correcting glasses.

The second part of the paper consists of a summary of the "shop laws" of the difterent States of the Union, which deal directly or indirectly with the eyes and eyesight. This contains much interesting and important matter, but cannot be abstracted.

A. J. Ballantyne.

\section{VI.-HEMIANOPIA IN BRAIN INJURIIES}

Best, F. (Dresden).-Hemianopia and sensory blindness in brain injuries. (Hemianopsie und Seelenblindheit bei Hirnverletzungen.) Arch.f. Ophthal., Vol. XCIII, Part i, I917.

Best has had the opportunity of observing numerous cases of head injury in the war in which hemianopia was one of the symptoms. In this lengthy paper he publishes notes of several of his more interesting observations. He points out the difficulty of accurate delineation of the fields of vision in such patients. The variations in the fields from day to day may be considerable. His results may be summed up as follows:

Of his hemianopia cases from war injury, 30.2 per cent. were double, $25 \cdot 6$ per cent. right sided and $44 \cdot 2$ per cent. left sided ; complete blindness as a result of double hemianopia was never observed. Death occurred in 12.8 per cent. One sided hemianopia with accurate limit through the fixation point occurred once, with complete destruction of the peripheral field, but preservation of the 
macula in 3.5 per cent. ; retention of the peripheral field with complete loss of the macula, never. These figures refer to cases on discharge. In recent cases of hemianopia the proportion of cases in which the inferior field was affected, 58.1 per cent., was much greater thản those in which the superior field suffered, $5 \cdot 8$ per cent. Paracentral double scotoma without damage to the peripheral field occurred in 3.5 per cent., double scotoma with damage to the peripheral field in 12.8 per cent., macular defect with peripheral destruction in 25.6 per cent., while in 38.4 per cent. there was only peripheral defect without scotoma or macular defect. In 18.6 per cent. the pupil on the aflected side was enlarged, in 7 per cent. that on the opposite side. In 10.5 per cent. nystagmus, in 4.7 per cent. abducens paresis, in 2.3 per cent. oculomotor paresis, and in one case total ophthalmoplegia were found. Incorrect optical localization regularly accompanies hemianopia. In 31.3 per cent. of cases number counting by eye was defective and in 5.8 per cent. there was optical agnosis. In $25^{\circ} 6$ per cent. alexia and in 14 per cent. agraphia was present.

In cases of hemianopia, which practically always occurs in injuries of the calcarine area, all sight functions in the affected parts of the field are damaged; there is no evidence of a special colour differentiation centre except in so far as sensory disturbances (aphasic) may be affected. The seat of the cerebral centre for optical localization is in the calcarine area, that for the upper part of the field being situated in the lower part of the calcarine fissure and that for the lower part of the field in the upper lip of the fissure. As regards the seat of the cerebral macula, Best has no fresh suggestion to offer, but considers that the theory postulating a seat for both halves of the macula in both hemispheres is highly improbable, since the escape of the macula is not a sharply defined circumference, but a more or less large remnant of a hemiamblyopic field in which the most important part has retained its function. The rarity of the complete destruction of half the field of vision is to be explained by the relatively large area of the calcarine, the destruction of the lower part of which completely is incompatible with life, owing to the proximity of the cerebellum.

The calcarine area is also the centre for reflex ocular movements, particularly those connected with fusion and convergence. It is also the centre for optical localization. Alexia and agraphia seem to follow more often left sided injury. In general, both these affections seem to be independent and not due to narrowing of the field for letters. Primitive visual injuries (such as number counting) occur equally in lesions of either side, but severe sensory blindness only in injuries of both sides.

E. E. H. 


\section{VII.-CONTUSION OF GLOBE AFTER SHOT INJURY}

\section{Igersheimer (Göttingen).--On the anatomy of contusion of the globe following shot injury. . (Zur Anatomie der Contusio Bulbi durch Schussverletzung.) Arch.f. Ophthal., Vol. XCIII, Pt. ii, I9I7.}

Igersheimer's case was a soldier of 29 , who came under observation six days after his wound. The wound of entry was on the left side of the forehead, near the hair margin, and that of exit near the right outer canthus. The right upper lid was somewhat swollen and red, the globe slightly proptosed and the pupil did not react. The vitreous was obscured by blood, but, when this had been cleared up, a rupture of the choroid concentric with the papilla became visible. It was also possible, a little later, to make out that the retina was uneven over the white area and that the vessels were partly obscured by the white mass. A coloured plate of the ophthalmoscopic appearances is given. Two months after the injury the man was marked for discharge, when meningitis suddenly set in and he died. Igersheimer obtained the globe and gives a minute account of its microscopical anatomy, illustrated with three text drawings. Histological examination showed that the grey-white mass seen with the ophthalmoscope was a subretinal scar tissue formation of the choroid which had projected in a spur-like way into the retina. In this area the retina was more or less atrophic. The choroid was split up in its anterior layers through the formation of scar tissue, and the destruction of the choriocapillaris and also to some extent of the large vessel layer, while the suprachoroidea was well preserved. Whether the proliferation of the choroidal tissue was the primary affection, and the disturbance of the pigment epithelium and posterior layers of the retina the second, or whether the tear in the pigment epithelium produced the other changes, or finally, the interference with the ciliary circulation was the underlying cause of all the other changes, could not be determined from the preparations.

Igersheimer adds a brief account of another eye in his possession, in which the final stages of such an injury are demonstrable. He gives no account of the nature of the injury in this case, but states that careful examination revealed no perforation or external injury. On one side the iris and ciliary body were normal. On this side the retina was degenerated near the ora serrata; corresponding with the degeneration, the pigment epithelium had proliferated. Then followed a broad band in which retina and pigment epithelium were well preserved. Further in, the retinal rods and cones were lost, and the pigment epithelium became irregular and wandered into the retina. Close to the papilla there was a scar between 
retina and choroid, as in the previous case. In the other half of the globe the retina was completely destroyed, as also the pigment epithelium and part of the choroid, their place being taken from the papilla to the ora serrata by scar tissue which was half the thickness of the sclera-and contained scattered pigment. The scar tissue was separated from the sclera by choroidal remnants (cross section of vessels and scattered pigment clumps). In the neighbourhood of the ora serrata the vitreous contained blood clot. The pigment layer of the ciliary body and iris was also affected, being partly destroyed and partly scattered through the tissue.

E. E. H.

\section{$\overline{\overline{2 e}}$ \\ VIII.-MISCELLANEOUS \\ (Third Notice)}

(I) Lo Cascio (Rome). - The composition of the pigment of melanotic sarcoma of the choroid. (Sulla costituzione del pigmento del sarcomi melanotici della coroide.) La Clin. Oculist., October, 1915.

(I) The examination of the pigment of these tumours hitherto has been faulty, says Lo Cascio, because the method employed to extract them has involved alteration of their composition. $\mathrm{He}$ thinks that he has been able to remove the pigment without disturbing it by means of copious washing with distilled water containing a few drops of chloroform.

He finds the percentage as follows:

C. $53 \cdot 17$ per cent. H. 6.16 per cent. N. 12.40 per cent. S. 2.53 per cent. Fe. 0.152 per cent. P. 0.294 per cent.

This agrees closely with the composition of the retinal and choroidal pigments of the normal eye, which two have been shown by Lo Cascio to be identical.

C. $54 \cdot 45$ per cent. H. $5 \cdot 88$ per cent. N. $12 \cdot 35$ per cent. O. $26 \cdot 08$ per cent. S. $1 \cdot 77$ per cent. P. 0.251 per cent. Fe. 0.101 per cent.

The small differences may be due to experimental errors.

\section{HaRold Grimsdale.}

(2) Lamb, Robert Scott (Washington)-Cyanosis retinae et conjunctivae in connection with pulmonary stenosis and patent ductus arteriosus. Trans. Amer. Ophth. Society, Vol. XIV, Part ii, I9I6.

(2) Lamb reports cyanosis of the conjunctiva and retina in a coloured girl, aged 13 years, believed to be aflected with pulmonary 
stenosis and patent ductus arteriosus of congenital origin. The condition of the retinal vessels is shown by two coloured plates. The vessels, as usual in such cases, were very tortuous and much dilated; the distinction between arteries and veins could be readily made. The palpebral conjunctiva was almost purple, and the bulbar conjunctiva was congested. The author makes some references to the literature of the condition.

S. S.

(3) Rochon-Duvigneaud, A. (Paris).- The protection of the cornea in crawling vertebrates (serpents and anguiliform fishes). [La protection de la cornée chez les vertébrés qui rampent (serpents et poissons anguiformes).] Ann. d'Ocul.. May, 1916.

(3) A. Rochon-Duvigneaud has studied the manner in which the corneae of serpents and anguiliform fish are protected. He finds that serpents have in front of the cornea a kind of watch glass formed by a transformation of the lower lid which has become fixed in front of the eye and transparent. There is a modified conjunctival sac between the cornea and the "watch glass," which latter is shed with the slough. In anguiliform fish (eels, etc.) a similar kind of protection is developed in a different way. In them the cornea consists of a superficial thick layer continuous with the skin and a deep thin layer continuous with the sclerotic between which there is a loose tissue consisting of parallel non-anastomosing fibres which functions as an intra-corneal articulation allowing the globe to be moved by its muscles under the cutaneous layer of the cornea which forms its protecting layer. There is no conjunctival sac.

\section{R. J. COUlter.}

\section{(4) Leenbeer, C. A. (Chicago). - An orbital endothelioma. Ophthal. Record, May, 1916.}

(4) Leenbeer has reported on this case of orbital endothelioma on two previous occasions. After removal of the tumour by Krönlein's orbital resection in 1905, the growth recurred. After 1906, and although it apparently never became larger than it was at the time it was excised, and never gave the patient any trouble, the eye and orbital contents were exenterated in 1915. The histological examination showed that the growth was a perivascular endothelioma.

The author's conclusions from this case are that: endotheliomata of the orbit are of slow growth and painless. They are prone to return at the site of the operation; but the neighbouring lymph nodes are not affected early:

Apparently, the growth was primarily one affecting the optic nerve or its sheath, but the writer does not say so.

J. Jameson Evans. 


\section{(5) Ferree, C. E. and Rand (Bryn Mawr College).-A résumé of experiments on the effects of different conditions of lighting on the eyes. Ann. of Ophth., Vol. XXV, No. 3 , July, 1916.}

(5) The object of the work by Ferree and Rand was to compare the effect of the different lighting conditions on the eye, and to find the factors in a lighting situation, which cause the eye to lose in efficiency and to experience discomfort. The paper mainly concerns itself with what are spoken of as the "distribution factors," viz., the evenness of illumination, the diftuseness of the light, the angle at which the light falls on the object viewed, and the evenness of surface brightness. The best control of these factors is got when dealing with a room properly lit by daylight; the next best, when an indirect system of artificial lighting is employed. The direct and semi-indirect systems are also considered. The investigations were by no means abstract in character. All the variations obtained were got by employing lighting installations in common use, and precise specifications of illumination eflects were made in each case. The conclusions arrived at may be very shortly summarised.-(1) The influence of the distribution factors is of the greatest importance. (2) In the direct and semi-indirect systems too much light is often used for the comfort and welfare of the eye. (3) The angle at which the light falls on the object is important, but is not nearly so important as evenness of the surface-brightness in the field of vision. (4) Of the systems of artificial lighting, that which runs the indirect method closest is the semi-indirect with reflectors having a high density. (5) The problem of installation is not so simple for the semi-indirect as for the wholly indirect reflectors. (6) The most difficult feature in the problem of protecting the eye is encountered in the lighting of rooms of low and medium height. (7) The loss of efficiency sustained by the eye in an unfavourable light seems to be muscular, and not retinal. (8) Eye shades are not an adequate substitute for lamp shades. (9) The observation of motion-pictures causes the eye to lose heavily in efficiency, and (10) there is a close relationship between loss of visual efficiency and ocular discomfort.

R. H. Elliot.

(6) Shahan, William E., and Lamb, Harvey D. (St. Louis)Histologic effects of heat on the eye. American Journal of Ophthulmology, August, 1916.

(6) Shahan and Lamb have experimented on the rabbit eye with the view of determining the effects of heat applied to the cornea. This was done by means of a "thermophor." The thermophor is a metal tube containing a thermometer and surrounded by a resistance coil to generate heat, while within the coil is placed a 
zinc-iron sensitive strip to permit the temperature to be kept at any constant point. Into one end of the metal tube are inserted applicators of various shapes to be applied directly to the cornea (See Journal of the American Medical Association, August 5, 1916).

In all the experiments, five in number, the applicator had a diameter of $7 \mathrm{~mm}$. and, in all, the time of application was ten minutes, but the degree of heat varied from 119 to 136 degrees Fahrenheit. The anatomical findings in detail must be sought in the original. The following are the authors' conclusions.

"We might, therefore, conclude from our findings that the immediate efiects of the heated applicator upon a rabbit's eye are first a swelling of the heated portion of the cornea due to a localized oedema, which with increase of heat is accompanied by destruction of the anterior epithelium, then a destruction of the posterior endothelial layer, further by a coagulation necrosis of Bowman's membrane and anterior layers of the substantia propria of the cornea, and lastly a swelling and coagulation necrosis of the iris. Later effects are: first, the appearance of the infiltration of the anterior layers of the cornea with polymorphonuclear leucocytes, then the formation of scar tissue and new blood-vessels to replace the destroyed substantia propria of the cornea. Lastly, the new connective tissue with its round pigment cells, where before was iris stroma."

ERnEst THOMSON.

\section{NOTES}

CAPtAin R. S. KennedY, R.A.M.C., was

Deaths. killed upon the field of honour in France in. 1918.

Azer Wahba, a prominent member of the Ophthalmological Society of Egypt, who was in charge of Ophthalmic Hospital at Zagazig, died suddenly in June last, at the age of 34 years.

Henry G. S. Warren, assistant ophthalmic surgeon, Royal Prince Alfred Hospital, died recently at Sydney, Australia.

Mortimer Frank, of Chicago, died on April 21, 1919, at the age of 45. He was ophthalmologist to the Michael Reese and to other hospitals. In matters of medical history he was an authority, and his library of rare medical books and engravings was extensive.

Frank van Fleet, of New York, died suddenly on April 5, 1919, at the age of 59. He was surgeon to the Manhattan Eye, Ear, and Throat Hospital. 